\title{
Droplet deposition density of organic liquid fertilizer at low altitude UAV aerial spraying in rice cultivation
}

\begin{abstract}
Megaclast-dominated fluvial systems have been largely ignored by researchers. Yet megaclasts exert an important control on channel geomorphology, flow behaviour and sediment transport, and such systems are probably far more common than this neglect would suggest. Despite the explicit identification of megaclasts as the products of cataclysmic flow, observation of modern fluvial systems confirms that megaclasts can be entrained by flows that lie within the normal flow regime. The pattern of fining along the megaclast-dominated Sabeto River of western Viti Levu, Fiji reveals a strong negative exponential relationship between particle size and distance downstream, and a rate of downstream fining comparable with that of other gravel-bed rivers. The downstream fining pattern is straightforward and step-like discontinuities in the fining gradient are absent. This is suggestive of a sedimentary system only minimally disrupted by the supply of sediment from tributaries or the reworking of material from sources such as hillslopes and alluvial terraces. There is evidence, however, of anomalously coarse sub-populations at two sites. These coarser components must predate the other deposits at the sites. We speculate that they represent the products of earlier and higher-magnitude events. The bed sediments may thus be composite features, made up of individual components each transported by a specific event of particular magnitude. Our work confirms the relationship between the rate of downstream fining and particle size. This may arise because the distance over which individual particles are transported is likely to be size dependent. It is also possible that abrasion may be more effective in the case of larger particles than smaller ones, with the result that the coarser fraction of the river's bed sediment fines downstream more rapidly than the finer fraction. There is a long-standing debate about the relative roles of abrasion and sorting in downstream fining. Our data reveal little evidence for a downstream increase in the roundness of the river's gravels, implying that abrasion is likely to play a minor role in the fining process in this system.
\end{abstract}

Keyword: Spray system; Crop fertilization; Water-sensitive paper; Droplet uniformity; Rice field 
